\title{
A comparison of South African and German extrinsic and intrinsic motivation
}

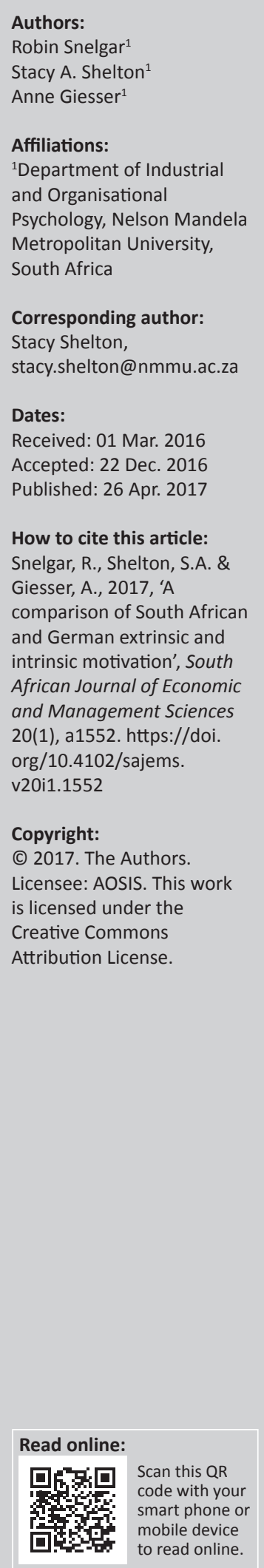

Authors:

Robin Snelgar

Affiliations:

Department of Industrial

Metropolitan University,

South Africa

Stacy Shelton,

Dates:

Accepted: 22 Dec. 2016

Giesser, A., 2017, 'A

comparison of South African

African Journal of Economic

d Management Sciences

v20i1.1552

Copyright:

Licensee: AOSIS. This work

is licensed under the

reative Commons

mobile device
Background: Various researchers have identified a trend of individuals shifting their preference from extrinsic to intrinsic motivation. The authors aimed to research this phenomenon specifically within the context of two different cultures as to date, this had not been done. This research explored the differing levels of extrinsic and intrinsic motivation in Germans and South Africans.

Aim: The main objective of this study was to investigate similarities and differences concerning extrinsic and intrinsic motivation in the workplace between German and South African cultures by examining individuals with working experience and tertiary education specifically. In addition, the research investigated differences in the motivation of respondents with regard to demographics such as gender, age and income.

Setting: The setting took place in South Africa and Germany.

Methods: In the study, exploratory factor analysis was utilised to prove validity of Cinar, Bektas and Aslan's two-dimensional measure of extrinsic and intrinsic motivation. Moreover, analysis of variance and $t$-tests were used to show differences among demographic variables. Descriptive statistics such as means, central tendency and Cronbach's alpha were also utilised.

Results: The results revealed preferences for intrinsic motivational factors for the whole sample with higher levels of intrinsic motivation for the South African respondents compared to German respondents. Demographic characteristics played a minor role in determining levels of intrinsic motivation within individuals. Culture, however, played the biggest role in determining one's levels of intrinsic or extrinsic motivation.

Conclusion: These findings play an important role in explaining differences in motivation between the two countries Germany and South Africa. It highlights the important role that cultural differences play in shaping one's form of motivation.

\section{Introduction}

To ensure job satisfaction in employees, it is important to know what motivates them to perform optimally. Motivation influences performance and for that reason has an impact on the productivity within a company (Halepota 2005).

On the one hand, in the global economy, geographical borders seem to matter less than in the past, while on the other hand cultural and social differences continue to influence people's motivation. Academic research thus far has focused mainly on the theoretical characteristics of motivation but has not taken into consideration the differences in the cultural and economic environments of various countries (Vaitkuviene, Balvociute \& Stoskus 2010). Employee motivation depends predominantly on the organisation; however, the impact of both the economic and social conditions in a country on an employee's motivation need to be considered as well (Vaitkuviene, Balvociute \& Stoskus 2010).

In the past organisations concentrated on financial factors as incentives for employees. Nowadays a shift has taken place, and non-financial rewards such as praise and recognition have become increasingly important, especially in the long term (Zani et al. 2011). Non-financial motivation is also needed, as the offer of financial incentives alone is likely to fail in attempting to motivate employees (Prendergast 2008).

Nawab, Bhatti and Shafi (2011) claim that motivation is the most crucial element of an employee's performance in general and, therefore, cannot be ignored. Anyim, Chid and Badejo (2012) state that it is crucial to understand that employees and companies are interdependent in the sense that 
employees require the organisation to reward them, both financially and non-financially, and the organisation requires the employees' services in return to make a profit. Furthermore, Molander (1996) highlights the important role that employees play in an organisation by saying that an organisation requires individuals who strive towards the achievement of the organisation's goals and have a strong commitment to the organisation, thus resulting in the organisation operating more efficiently and attaining success. The required level of dedication and commitment can be stimulated through increasing employees' motivation (Mundhra \& Jacob 2011). A rise in motivation and work commitment leads to an increase in both personal and organisational development as well as increased efficiency in the workplace (Ciorbagiu-Naon 2010).

South Africa and Germany differ in terms of social norms, culture and standard of living (Francesco \& Gold 2005). Therefore, this research aims to investigate sources of motivation in an international context, specifically looking at South Africa and Germany. This could be useful for international organisations when designing, implementing or revising their reward system.

Based on the above background, the purpose of this study is to investigate the importance of extrinsic and intrinsic motivation in an international context, using Germany and South Africa as sample countries. Additionally, the research aims to investigate differences between types of motivation respondents possess with regard to demographics such as gender, age and income.

\section{Literature review}

Robbins and Judge (2011) define motivation as the processes which account for an individual's intensity, direction and persistence towards reaching a particular goal. Before the development of Human Resource Management roles, personnel were regarded merely as an input in manufacturing goods and providing services and as an asset rather than an investment, whereas nowadays the motivation of employees is considered an integral part of organisations' optimal functioning (Perkins \& White 2009). The change in thought was as a result of the Hawthorne Studies, which examined productivity and working conditions (Robbins \& Judge 2011). The results of this study revealed that the positive working relationships and interactions affected productivity more so than the working environment did (Khan, Riaz \& Rashid 2011). Thus, this suggested that management could effectively influence employees' motivation through interactions and rewards rather than through the adjustment of the working environment. The earliest research on motivation concentrated on two main types of explanations for behaviour: natural desires or ambitions linked to existence and reproduction (e.g. hunger, thirst and sex) and extrinsic rewards or penalties. Both approaches propose that behaviour is driven by the necessity for aspiration to accomplish specific results (e.g. a reward, or escaping punishment).
Motivation accordingly invigorates and channels behaviour to achieve a specific goal (Sansone \& Harackiewicz 2000).

The early theories of motivation built the foundation for research in motivation. They are Maslow's hierarchy of needs, Theory X and Y, the Two- Factor Theory by Herzberg and McClelland's Theory of Needs (Robbins \& Judge 2011). The earlier theories are classified as content theories, which pinpoint causes or needs connected with motivation. These theories limit the description of motivation to a specific number of factors and only explain how to motivate people under these circumstances (Francesco \& Gold 2005). Despite current research, which has produced new insights into motivation, the early theories are still used in practice by many managers and so form an important base (Udechukwu 2009).

Process theories, such as Reinforcement Theory, Goal Setting Theory, Expectancy Theory and Equity Theory, pay more attention to the activity than to the content (Francesco \& Gold 2005). Process theories help one to understand how behaviour is started, guided, sustained and stopped (Jalilvand \& Ebrahimabadi 2011). The approach of Self-determination Theory is important for researching motivational theories; even if it sometimes differs from existing motivational strategies.

There are two main categories of motivation which are focused on in this study, namely extrinsic and intrinsic motivation.

\section{Extrinsic motivation}

Extrinsic motivation describes the effect of external factors on an employee's motivation level (Qayyum \& Sukirno 2012). It is motivation which originates from outside a person and motivation in this context can be considered extrinsic rewards, for example, financial incentives and status. These rewards should compensate for the lack of fulfilment and enjoyment regarding the actual task (Thomas 2009). When extrinsic motivation is used incorrectly, this may result in employees shifting their focus towards only achieving financial gain. This may, therefore, divert their attention away from developing his or herself to being mainly focused on completing a task purely for financial gain (Zobal 1999). Furthermore, this author states that financial rewards may lead to negative effects on employees when goals are not achieved, such as a lack of confidence or being demotivated. Zobal (1999) states that financial rewards may strip employees of the pride associated with their work.

Salary, benefits and incentives are examples of extrinsic motivators (Qayyum \& Sukirno 2012). Researchers disagree about the role of money as a motivator (Khalid, Salim \& Loke 2011). Although financial rewards can have a number of negative impacts, organisations still look for some monetary opportunities to motivate their employees (Prendergast 2008). Taylor (2007) claims that money is the best motivator. However, Anyim et al. (2012) point out that motivation 
depends on various factors and is fairly complex. For example, the economic conditions of a country affect the significance of money to its people. These same authors maintain that although cash is an important stimulus for low-income groups, it does not have the same importance for high-earning individuals, who have already satisfied their basic needs.

In contrast, Darling, Arm and Gatlin (1997) claim that nowadays researchers and practitioners are aware of several drawbacks of monetary rewards, as monetary driven motivation is often short-lived. According to Mundhra and Jacob (2011), extrinsic motivation is built on external factors and is only temporary. Extrinsically motivated behaviours are linked to basic ambitions, which normally work in the form of a cycle that disturbs intrinsically motivated behaviour (Deci \& Ryan 1985). For this reason, money is usually only the means to an end, and which has negative consequences.

Referring to 128 experiments Ryan and Deci (2000) claim that tangible rewards seem to have a considerably undesirable influence on intrinsic motivation. Pink (2009) claims that autonomy, mastery and purpose are three elements which enable a workforce to be motivated, more so than extrinsic monetary rewards.

\section{Intrinsic motivation}

Intrinsically motivated undertakings are the ones for which the action itself is the reward. Individuals appear to participate in the activities because of the enjoyment derived from the task and not because of the expectation of receiving an extrinsic reward (Deci 1975; Ryan \& Deci 2000; Deci \& Ryan 2008). The task itself or the related target satisfies a direct need in its own right. Intrinsic motivation reveals an individual's core aspiration for meeting internal needs, and it originates from emotions (Qayyum \& Sukirno 2012).

Frey and Osterloh (2002) claim that intrinsic motivation is highly important for every action in the business world. Intrinsic motivation is considered to be the main influential dynamic behind the creative process in business (Hennessey 2000). It is unimaginable that employees are only or even mostly motivated by extrinsic rewards and it is for this reason that intrinsic rewards are so essential (Pink 2011). If intrinsic motivation develops as a consequence of selfdetermination and a feeling of ability combined, then a reward can motivate individuals to manage tasks which are original and observed as extremely difficult at the outset. As the individual's knowledge increases over a period of time, new intrinsic motivation is encouraged (Frey \& Osterloh 2002).

Osterloh and Frost (2002) claim that the management of intrinsic motivation has been neglected. Present management systems have also failed to address this matter. Instead these management systems have concentrated on extrinsic financial remuneration systems (Osterloh \& Frost 2002).

\section{Relationship between extrinsic and intrinsic motivations}

The fulfilment employees develop from the intrinsic features of their work, such as responsibility and task attraction, is imperative for intrinsic motivation and retention in the organisation more so than extrinsic rewards (for instance, monetary benefits) (Burke, Arkowitz \& Dunn 2002).

According to Arnolds et al. (2010), it is still uncertain which intrinsic and extrinsic factors in particular motivate employees. Occasionally a verbal 'thank you' is sufficient, whereas with some individuals this may not be the case. The difficulty in rewards is that unrewarded accomplishments on the jobs can be de-motivating to employees (CiorbagiuNaon 2010).

Previously it was assumed that extrinsic and intrinsic motivation acted independently of each other. However, various socio-psychological researchers have revealed that an interchange between intrinsic and extrinsic motivation can be found. For example, children, who are enthusiastic about their schoolwork in the beginning, show less interest in the activity itself after being offered a reward (Frey \& Osterloh 2002). Ryan and Deci (2000) provided evidence that individuals in general, and not necessarily only school children, show less interest in something which was previously only intrinsically rewarding as soon as an extrinsic reward is introduced.

\section{Motivation in the context of demographics}

Variables such as gender, age, literacy, work experience, relationship status and the number of children can influence the perception and preference of employees regarding certain rewards (Ciorbagiu-Naon 2010). The section that follows discusses the differences according to gender, age, income and culture with regard to intrinsic motivation.

\section{Gender and motivation}

Research regarding the relationship between gender and motivation is contradictory. While Worthley, MacNab, Brislin, Ito and Rose (2009) found that gender has an influence on motivation, Stettes and Zimmermann (2013) state that gender has a minimal influence on motivation as women are only slightly more motivated than men.

\section{Age and motivation}

Each generation has its own values and is influenced by different external conditions. For this reason, they are motivated by different rewards (Smith 2010). Thus, motivation and reward strategies should be modified and orientated towards these groups of the workforce (Grobler, Wärnich, Carell, Elbert \& Hatfield 2011). Truxillo (2009) and Inceoglu, Bartram and Segers (2012) showed that mature individuals (i.e. individuals 50-59 and 60+) were more motivated by intrinsically rewarding work attributes than by extrinsically rewarding ones. However, Snelgar, Renard and Venter (2013) report that in their study investigating reward 
preferences, older employees showed a stronger preference for base and variable pay when compared to their younger counterparts.

\section{Income and motivation}

The results of the research conducted by Del Mar, SalinasJimenez, Arte and Salinas-Jimenez (2010) reveal that the higher the life satisfaction of an individual, the more likely the individual will be to switch from extrinsic to intrinsic motivation. These authors revealed that this occurred irrespective of income.

Nowadays two entirely contradictory opinions of the motivational influence of pay exist. The first approach states that a rise in pay has an encouraging effect on the worker, who then willingly puts more effort into his work. The second approach claims that a rise in pay essentially undermines motivation and could lead to a decrease in performance (Deci 1975). Del Mar et al. (2010) note that it is generally the higher level income groups which experience the most intrinsic motivation. Renard's (2015) study on a sample of 587 employees within the non-profit sectors in South Africa, USA, Australia and Belgium revealed the same result that higher income groups experience higher levels of intrinsic motivation. This may be because of the fact that their external, physical needs have already been fulfilled as they are earning more extrinsic rewards (i.e. more money and better benefits).

\section{Culture and motivation}

Culture can be described as the personality of a region and incorporates objective (e.g. cuisine, art and dressing) as well as the subjective (e.g. attitudes, beliefs and values) criteria (Worthley et al. 2009). Factors influencing motivation differ between countries and cultures (Francesco \& Gold 2005). According to Hofstede's cultural framework (Hofstede 2001), Germany and South Africa do not seem to have many differences. Francesco and Gold (2005) state that Germany has a smaller power distance than what South Africa does, and has a higher level of uncertainty avoidance. Hofstede (2001) defines power distance as the extent to which less powerful individuals within an organisation existing within a particular culture accept and expect an unequal distribution of power, whereas uncertainty avoidance is defined as the degree to which members of a culture feel comfortable in unstructured situations. Germany and South Africa seem to be similarly individualistic and demonstrate a similar level of masculinity in their cultures, however. Hofstede (2001) describes masculine cultures as cultures which emphasise achievement and accomplishment in technical performance, whereas more feminine cultures place greater emphasis on interpersonal relationships and communication. The most important difference between South Africa and Germany, however, is that standards of living are different (Francesco \& Gold 2005). These differences might have influences on motivational factors.

To date there is no study which compares the difference in motivation between South Africa and Germany. However, a recent study which took place in Germany specifically on public sector employees revealed that these German workers were highly intrinsically motivated (Kaiser 2014). In addition, research by Schmuck, Kasser and Ryan (1999) portrays Germans as being more motivated by intrinsic goals, especially those which improve well-being. Generally they are less extrinsically motivated than other cultures (e.g. the USA).

Pay is not the most important thing for German employees. An important need for German employees is the opportunity to influence, to be able to put forward their own ideas, to be involved in decision-making and to help shape guidelines and targets agreements (Stettes \& Zimmermann 2013). Thus, this suggests that German employees place more importance on intrinsic rewards and are intrinsically motivated.

South African research, on the other hand, shows that adequate pay was the most important issue for South African employees. This was closely followed by the desire for development opportunities, equality and recognition (Van Rooyen, du Toit, Botha \& Rothmann 2010). However, Nujjoo and Meyer (2012) have found that in South Africa the positive influence of non-monetary and particularly intrinsic rewards can lead to highly skilled individuals becoming more committed and intrinsically motivated. Renard's (2015) study revealed too that South African employees in general exhibit higher levels of intrinsic motivation than other countries (this study investigated differences in intrinsic motivation between South Africa, USA, Belgium and Australia).

\section{Hypotheses}

From the above literature review, the following research questions were generated:

- What are the differences between the German and South African cultures in the context of extrinsic and intrinsic motivation in the workplace?

- What correlations exist between motivation and various demographical data?

Thus, the hypotheses which result from the literature and are relevant to this research are listed below:

H1: A difference in extrinsic and intrinsic reward motivation exists between South African and German cultures.

H2: The correlation between culture and motivation is stronger than the correlation between gender and motivation.

H3: The correlation between age and motivation is stronger than the correlation between culture and motivation.

H4: The higher the income, the greater the preference for intrinsic motivation.

\section{Research methodology}

This research is non-experimental, descriptive and quantitative in nature. Data collection occurred during May and July 2013. 


\section{Pilot study}

The researcher conducted a pilot study to ascertain language problems with the questionnaire or scales, and to conduct a trial of some of the analysis procedures to be undertaken in the main study. The pilot study included 20 working individuals and was conducted in April 2013. The pilot study produced satisfactory Cronbach's alpha results (0.83-0.84). However, in the pilot study the results of the exploratory factor analysis were not satisfactory enough. The statistics specialist pointed out that there might be different factors for the two different countries, but unfortunately the sample size did not permit an exploratory factor analysis per country (D. Venter [statistician, Unit for Statistical Consultation, Nelson Mandela Metropolitan University] pers. comm., 16 August 2013). For this reason, the researcher and the statistical expert agreed to proceed with the research instrument and to work with the results of the main study.

\section{Research method and respondents}

Non-probability sampling was used in the form of convenience and snowball sampling. The researcher made use of existing contacts and distributed the questionnaire by means of email.

The following control measures had to be put in place for the target population. The respondents had to be either German or South African. These two countries were selected so as to have one European country represented and one African country. It allowed for a comparison between developed and non-developed countries. This was verified by a mandatory question in the demographic section. The respondents were also required to have work experience and a tertiary education. Additionally, the respondents were asked questions pertaining to their gender, age, marital status, managerial position at work and annual income. A total of 256 people were contacted via email and asked to participate in this study, as well as to forward the questionnaire to colleagues who fit the relevant criteria. In total, 374 individuals fully completed the online questionnaire, including 193 Germans and 181 South African respondents. This sample size was deemed adequate for this research by the researchers' statistician.

Table 1 shows the characteristics of the sample with regards to nationality, gender, age, marital status, and annual income. As can be gleaned from the table, $52 \%$ of respondents were German and the remaining $48 \%$ are South African. As evident from Table 1, the majority of the sample was male (52\%), and female respondents made up the remaining $48 \%$.

Age was split into five categories: 20-29, 30-39, 40-49, 50-59 and $60+$. From Table 1, it can be seen that the majority of the sample was made of respondents between the ages of 30 and $39(38 \%)$, followed by respondents between the ages of 40 and $49(21 \%)$ and 20 and $29(20 \%)$.

Table 1 shows that the vast majority of the sample is married $(57 \%)$, followed by those in a relationship (26\%).
Finally, Table 1 shows the characteristics of the sample according to annual income. However, as the sample incudes respondents from Germany and South Africa, and these two countries have different currencies and the Euro is a stronger currency than the rand; respondents had to be grouped into similar annual income groups for ease of comparison. Table 2 provides the breakdown of the income groups. As is evident from Table 1, the majority of the respondents in this sample fall into income group 6 (above R600 000 or above $€ 60000$ annually), followed closely by income group 2 (R120 000-R239 000 or €12 000-€23 999 annually).

Finally, the table shows that $48 \%$ of the sample is not in a managerial position, with $42 \%$ in a managerial position and $10 \%$ in a supervisory role more than a managerial position.

\section{Measuring instrument}

The questionnaire was designed by Cinar, Bektas and Aslan (2011) as a two-dimensional measure of extrinsic and intrinsic motivation. Questions 1-9 dealt with intrinsic motivation and questions 10-24 with extrinsic motivation. The researcher obtained permission from the developer regarding the questionnaire to use it and adapted it accordingly. As the questionnaire would be answered by both English and German speakers, the researcher felt it was necessary to adapt the level of English to accommodate both countries.

TABLE 1: Sample characteristics $(n=374)$.

\begin{tabular}{|c|c|c|c|}
\hline Variable & Item & $f$ & $\%$ \\
\hline \multirow[t]{2}{*}{ Nationality } & South African & 193 & 52 \\
\hline & German & 181 & 48 \\
\hline \multirow[t]{2}{*}{ Gender } & Male & 195 & 52 \\
\hline & Female & 179 & 48 \\
\hline \multirow[t]{5}{*}{ Age } & $20-29$ & 73 & 20 \\
\hline & $30-39$ & 144 & 38 \\
\hline & $40-49$ & 78 & 21 \\
\hline & $50-59$ & 60 & 15 \\
\hline & $60+$ & 19 & 5 \\
\hline \multirow[t]{4}{*}{ Marital status } & Single & 51 & 13 \\
\hline & In a relationship & 96 & 26 \\
\hline & Married & 213 & 57 \\
\hline & Divorced/widowed & 14 & 4 \\
\hline \multirow[t]{6}{*}{ Annual income } & Income group 1 & 32 & 9 \\
\hline & Income group 2 & 79 & 21 \\
\hline & Income group 3 & 67 & 18 \\
\hline & Income group 4 & 50 & 13 \\
\hline & Income group 5 & 51 & 14 \\
\hline & Income group 6 & 95 & 25 \\
\hline \multirow[t]{3}{*}{ Managerial position } & Managerial position & 158 & 42 \\
\hline & Not in managerial position & 180 & 48 \\
\hline & Not managerial, more supervisory & 36 & 10 \\
\hline
\end{tabular}

TABLE 2: Overview of income groups.

\begin{tabular}{lll}
\hline Income group & Rand & Euro \\
\hline 1 & Below 120 000 & Below 12.000 \\
2 & $120000-239999$ & $12.000-23.999$ \\
3 & $240000-359999$ & $24.000-35.999$ \\
4 & $360000-479999$ & $36.000-47.999$ \\
5 & $480000-599999$ & $48.000-59.999$ \\
6 & Above 600 000 & Above 60.000 \\
\hline
\end{tabular}


The specific rating scale that was used in the questionnaire was the Likert scale, which forces the respondents to reveal their degree of agreement or disagreement with each of a number of statements about the stimulus object (Malhotra 2010). A five-item scale was decided upon, which had five response categories ranging from 'not at all motivating' to 'highly motivating'.

The questionnaire is divided into two sections consisting first of questions about intrinsic motivation, followed by extrinsic motivation. These sections were followed by the demographic questions.

\section{Research procedure}

Once the questionnaire had been selected, the researcher chose to use an electronic survey method, as this was the easiest and most convenient method for reaching the wide spread target group.

\section{Data analysis}

Both inferential (analysis of variance, $t$-tests) and descriptive statistics (measures of central tendency, mean scores, and Cronbach's alpha) were used for data processing. The statistical package STATISTICA, version 11.0, and SPSS 9.0 were utilised for this purpose.

\section{Results}

\section{Descriptive statistics and Cronbach's alpha coefficients}

Table 3 shows the descriptive statistics for the sample. The means, standard deviation, minimum and maximum are all included for intrinsic factors, extrinsic factors and overall. As is evident from this, the levels of intrinsic motivation were the highest (mean of 4.17 out of 5 ), with extrinsic motivation being rated as moderately high.

Table 3 also provides the Cronbach's alpha coefficients for the study. These scores show an acceptable level of reliability as they are above the 0.60 level (Maholtra 2010).

Table 4 shows the intervals for the means so that one may interpret how strong the motivation is for that particular type of motivation.

\section{Validity}

The validity of a scale can be defined as the determination of whether the scale measures what it is intended to measure (Phillips \& Gully 2012). In order to show that the questionnaire demonstrated acceptable validity, the researcher conducted an exploratory factor analysis. The results of this are presented in Table 5 The table shows that the questionnaire comprised of five factors as five of the factors are above the 1.0 level cut-off (Maholtra 2010).

Once established that there were five factors, the researchers established which questions loaded onto which factors. A factor loading of 0.30 is considered as significant for a sample size higher and larger than 350 (Hair, Black, Babin \& Anderson 2010). Table 6 shows which items loaded onto which factor, by highlighting the questions above the 0.30 level for that factor. Based on Table 6, the questions have been grouped into factors as shown in Table 7.

It is important to note that questions 6, 7 and 11 do not load onto any factor. Questions 14, 18 and 21 load into more than one factor, with question 14 loading onto factors 1 and 2, question 18 loading onto factors 1 and 3, and question 21 loading onto both factors 3 and 5 . However, for question 14, factor 2 had a higher loading, for question 18, factor 3 had a higher loading, and for question 21, factor 3 had a higher loading. This then determined the factor loading for these questions. Moreover, it is important to note that the questions which pertained to pure intrinsic rewards related to factors such as autonomy, and mastery which Renard (2015) previously identified as 'pure intrinsic rewards' in that they link entirely to the job itself and not to any other external sources.

\section{Hypotheses}

\section{Hypotheses}

This section will discuss the set hypotheses and present the tables which show whether they may be accepted or rejected.

\section{Hypothesis 1}

Table 8 reveals that overall the sample demonstrates moderately high levels for intrinsic motivation and moderately high levels for extrinsic motivation. These differences are statistically significant $(p<0.05)$.

Table 9 provides evidence that German respondents are intrinsically motivated at a moderately high level and extrinsically motivated at a moderately high level as well.

\begin{tabular}{ll} 
TABLE 4: Intervals for motivation. & \\
\hline Range & Classification \\
\hline $1.0-1.8$ & No motivation \\
$1.9-2.6$ & Low motivation \\
$2.7-3.4$ & Neutral \\
$3.5-4.2$ & Moderate motivation \\
$4.3-5.00$ & High motivation \\
\hline
\end{tabular}

TABLE 3: Descriptive statistics for sample $(n=374)$.

\begin{tabular}{lllll}
\hline Motivations & Mean & Std. Dv. & Minimum & Maximum \\
\hline Intrinsic motivation & 4.17 & 0.49 & 1.00 & 5.00 \\
Extrinsic motivation & 3.75 & 0.53 & 1.00 & 0.82 \\
Overall motivation & 3.91 & 0.87 & 1.00 & 0.00 \\
\hline
\end{tabular}

Std. dev., standard deviation. 
TABLE 5: Exploratory factor analysis results.

\begin{tabular}{|c|c|c|c|c|}
\hline Extraction: principal components & Eigenvalue & $\%$ Total variance & Cumulative eigenvalue & Cumulative $\%$ \\
\hline 1 & 6.78752096 & 28.2813373 & 6.78752096 & 28.2813373 \\
\hline 2 & 2.26239947 & 9.42666445 & 9.04992043 & 37.7080018 \\
\hline 3 & 1.54410323 & 6.43376344 & 10.5940237 & 44.1417652 \\
\hline 4 & 1.35387565 & 5.64114855 & 11.9478993 & 49.7829138 \\
\hline 5 & 1.16016015 & 4.83400062 & 13.1080595 & 54.6169144 \\
\hline 6 & 0.987077507 & 4.11282295 & 14.095137 & 58.7297373 \\
\hline 7 & 0.943475196 & 3.93114665 & 15.0386122 & 62.660884 \\
\hline 8 & 0.904919016 & 3.7704959 & 15.9435312 & 66.4313799 \\
\hline 9 & 0.784546996 & 3.26894582 & 16.7280782 & 69.7003257 \\
\hline 10 & 0.73012874 & 3.04220308 & 17.4582069 & 72.7425288 \\
\hline
\end{tabular}

TABLE 6: Factor loadings.

\begin{tabular}{|c|c|c|c|c|c|}
\hline \multirow[t]{2}{*}{ Questions } & \multicolumn{5}{|c|}{ Factor } \\
\hline & 1 & 2 & 3 & 4 & 5 \\
\hline Q1 & 0.066 & -0.119 & -0.027 & $0.418 \dagger$ & 0.276 \\
\hline Q2 & 0.157 & -0.029 & -0.120 & $0.453 \dagger$ & 0.144 \\
\hline Q 3 & -0.037 & 0.271 & 0.018 & 0.007 & $0.559 \dagger$ \\
\hline Q 4 & 0.077 & -0.040 & -0.002 & 0.240 & $0.508 \uparrow$ \\
\hline Q 5 & -0.100 & 0.081 & 0.173 & $0.687 \dagger$ & -0.026 \\
\hline Q 6 & 0.083 & 0.127 & 0.076 & 0.303 & 0.318 \\
\hline Q 7 & 0.188 & 0.094 & 0.060 & 0.252 & 0.308 \\
\hline Q 8 & 0.034 & -0.017 & -0.043 & $0.720 \dagger$ & -0.024 \\
\hline Q9 & 0.177 & -0.057 & 0.118 & 0.135 & $0.496 \dagger$ \\
\hline Q 10 & -0.069 & $0.364 \dagger$ & 0.030 & 0.174 & 0.112 \\
\hline Q 11 & 0.276 & 0.337 & 0.060 & 0.064 & 0.133 \\
\hline Q 12 & 0.015 & $0.621 \dagger$ & 0.114 & 0.105 & -0.149 \\
\hline Q 13 & 0.221 & 0.298 & 0.178 & 0.258 & -0.086 \\
\hline Q 15 & $0.479 \dagger$ & 0.164 & 0.014 & 0.089 & -0.079 \\
\hline Q 16 & $0.600 \dagger$ & 0.112 & 0.084 & 0.104 & -0.148 \\
\hline Q 17 & $0.714 \dagger$ & 0.000 & -0.076 & -0.075 & 0.176 \\
\hline Q 18 & $0.427 \dagger$ & -0.132 & $0.441 \dagger$ & 0.069 & 0.046 \\
\hline Q 19 & $0.603 \dagger$ & -0.066 & 0.146 & 0.033 & 0.135 \\
\hline Q 20 & -0.091 & 0.048 & $0.863 \dagger$ & 0.026 & 0.060 \\
\hline Q 21 & 0.078 & -0.113 & $0.453 \dagger$ & 0.012 & $0.443 \dagger$ \\
\hline Q 22 & 0.100 & $0.587 \dagger$ & -0.058 & -0.158 & 0.135 \\
\hline Q 23 & 0.137 & $0.452 \dagger$ & 0.194 & -0.109 & -0.021 \\
\hline Q 24 & 0.105 & 0.168 & $0.476 \dagger$ & -0.029 & -0.044 \\
\hline
\end{tabular}

$\dagger$, significant factor loading.

$\mathrm{Q}$, question.

TABLE 7: Summary of factors and related questions.

\begin{tabular}{ll}
\hline Factors & Questions \\
\hline Relational (factor 1) & $15,16,17,19$ \\
Benefits (factor 2) & $10,12,14,22,23$ \\
Recognition (factor 3) & $18,20,21,24$ \\
Pure intrinsic rewards (factor 4) & $1,2,5,8$ \\
Respect and prestige (factor 5) & $3,4,9$ \\
\hline
\end{tabular}

However, they are slightly more intrinsically motivated than extrinsically motivated.

Table 10 shows that South African respondents are highly intrinsically motivated and moderately highly extrinsically motivated. Based on this, it is evident that the South African respondents are more intrinsically and extrinsically motivated than their German counterparts.

Hypothesis 1 stated that a difference in motivation exists between the South African and German cultures. As is evident from the tables above, all the $p$-values are below 0.01 , which indicates significant differences between South Africa and Germany in terms of motivation. Based on the means provided in the table, it is clear that South Africans are more motivated by intrinsic and extrinsic motivation than what Germans are. Therefore, H1 can be accepted.

\section{Hypothesis 2}

Hypothesis 2 stated that the correlation between culture and motivation is stronger than the correlation between gender and motivation. Table 11 shows the differences between the two countries in terms of motivation as characterised by gender. One can glean from the table that German females were more motivated by intrinsic and extrinsic factors than what German males were. South African females were also more motivated by intrinsic and extrinsic factors than South African males. Overall, females in the sample were more motivated by intrinsic and extrinsic factors than the males were. However, in all instances the difference was not large enough to be significant $(p>0.05)$. Consequently, cultural 
TABLE 8: $t$-Test results across the sample $(n=374)$.

\begin{tabular}{lllllll}
\hline Motivations & Mean & Std. Dv. & $\boldsymbol{N}$ & Diff. & Std. Dv. Diff. & $\boldsymbol{t}$ \\
\hline Intrinsic motivation & 4.17 & 0.49 & - & - & - & - \\
Extrinsic motivation & 3.75 & 0.53 & 374.00 & 0.42 & $0.00^{*}$ & 0.49 \\
\hline
\end{tabular}

Std. Dv., standard deviation; diff, difference.

$*, p>0.05=$ statistically significant.

TABLE 9: $t$-Test results for Germany $(n=194)$.

\begin{tabular}{lllllll}
\hline Motivations & Mean & Std. Dv. & $\boldsymbol{N}$ & Diff. & Std. Dv. Diff. & $\boldsymbol{t}$ \\
\hline Intrinsic motivation & 4.01 & 0.48 & & & & \\
Extrinsic motivation & 3.58 & 0.48 & 193.00 & 0.43 & $0.00^{*}$ & 0.51 \\
\hline
\end{tabular}

Std. Dv., standard deviation; diff, difference; $N$, sample.

$*, p>0.05=$ statistically significant.

TABLE 10: $t$-Test results for South Africa $(n=180)$.

\begin{tabular}{lllllll}
\hline Motivations & Mean & Std. Dv. & $N$ & Diff. & Std. Dv. Diff. & $\boldsymbol{t}$ \\
\hline Intrinsic motivation & 4.35 & 0.43 & & & & \\
Extrinsic motivation & 3.94 & 0.52 & 181.00 & 0.42 & $0.00^{*}$ & 0.47 \\
\hline
\end{tabular}

Std. Dv., standard deviation; diff, difference; $N$, sample.

$*, p>0.05=$ statistically significant.

TABLE 11: $t$-test results according to age.

\begin{tabular}{|c|c|c|c|c|c|c|c|}
\hline Home country & Motivation & Mean female & Mean male & $t$-value & $p$ & Std. Dv. female & Std. Dv. male \\
\hline \multirow[t]{2}{*}{ Motivations } & Intrinsic & 4.21 & 4.13 & 1.63 & 0.10 & 0.51 & 0.46 \\
\hline & Extrinsic & 3.79 & 3.71 & 1.52 & 0.13 & 0.51 & 0.55 \\
\hline \multirow[t]{2}{*}{ Germany } & Intrinsic & 4.05 & 3.97 & 1.11 & 0.27 & 0.53 & 0.42 \\
\hline & Extrinsic & 3.63 & 3.53 & 1.48 & 0.14 & 0.47 & 0.49 \\
\hline \multirow[t]{2}{*}{ South Africa } & Intrinsic & 4.37 & 4.33 & 0.59 & 0.56 & 0.43 & 0.43 \\
\hline & Extrinsic & 3.94 & 3.93 & 0.13 & 0.90 & 0.50 & 0.55 \\
\hline
\end{tabular}

Std. Dv., standard deviation.

differences are more significant than gender difference as Table 8 previously provided evidence which showed that there was a significant difference between cultures with regard to motivation, both intrinsic and extrinsic. Thus, H2 can be accepted.

\section{Hypothesis 3}

Hypothesis 3 stated that the correlation between age and motivation is stronger than the correlation between culture and motivation. Table 12 shows the mean scores according to age, whereas Table 13 shows the ANOVA results according to age for intrinsic and extrinsic motivation.

As is evident from the table, the group with the highest mean score for intrinsic motivation is the age group 50-59 years, and the group with the highest mean score for extrinsic motivation, interestingly, is also the same age group. This, therefore, suggests that this age group has the highest levels of intrinsic and extrinsic motivation.

Table 13 shows that there is a statistically significant difference according to age with regard to intrinsic motivation only. There is no statistically significant difference according to age with regard to extrinsic motivation across the sample $(p>0.05)$.

Referring to Table 8 , this shows differences according to culture. From this it is clear that both intrinsic and extrinsic motivations had statistically significant differences for both countries, whereas there is only a statistically significant difference according to age with regard to extrinsic motivation. Thus, H3 is partly accepted.

\section{Hypothesis 4}

Hypothesis 4 stated that the higher the income, the greater the preference for intrinsic motivation. In Table 14 the means of the different income groups for intrinsic and extrinsic motivation are presented. From the table it is evident that interestingly, the lowest income group had the highest mean score for intrinsic motivation and also the highest mean score for extrinsic motivation.

Table 15 shows the marked differences according to the various income groups. The $p$-value for intrinsic motivation is above 0.05 and therefore is not statistically significant but the $p$-value for extrinsic motivation is below 0.01 and therefore is statically significant. This shows that a preference for intrinsic motivation does not increase as income increases; instead it is extrinsic motivation that increases. It is the lowest income group which shows the highest level of extrinsic motivation. Therefore, $\mathrm{H} 4$ can be rejected.

\section{Discussion}

\section{Differences in motivation between South Africa and Germany}

The main finding of this study showed that significant differences did exist in terms of motivation between South Africa and Germany. This was found in the case of 
TABLE 12: Mean scores according to age.

\begin{tabular}{|c|c|c|c|c|}
\hline \multirow[t]{2}{*}{ Age } & \multicolumn{2}{|c|}{ Intrinsic motivation } & \multicolumn{2}{|c|}{ Extrinsic motivation } \\
\hline & Means & Std. Dv. & Means & Std. Dv. \\
\hline $20-29$ years & 4.02 & 0.53 & 3.74 & 0.50 \\
\hline 30-39 years & 4.18 & 0.48 & 3.72 & 0.53 \\
\hline 40-49 years & 4.24 & 0.45 & 3.74 & 0.55 \\
\hline $50-59$ years & 4.27 & 0.42 & 3.88 & 0.49 \\
\hline $60+$ years & 4.13 & 0.56 & 3.67 & 0.66 \\
\hline All groups & 4.17 & 0.47 & 3.75 & 0.53 \\
\hline
\end{tabular}

Std. Dv., standard deviation.

TABLE 13: ANOVA results according to age.

\begin{tabular}{|c|c|c|c|c|c|c|c|c|}
\hline \multirow[t]{2}{*}{ Motivations } & \multicolumn{3}{|c|}{ Effect } & \multicolumn{3}{|c|}{ Error } & \multirow[t]{2}{*}{$F$} & \multirow[t]{2}{*}{$p$} \\
\hline & SS & $d f$ & MS & SS & $d f$ & MS & & \\
\hline Intrinsic & 2.76 & 4 & 0.69 & 85.43 & 369 & 0.23 & 2.98 & $0.02 *$ \\
\hline Extrinsic & 1.26 & 4 & 0.32 & 103.49 & 369 & 0.282 & 1.12 & 0.34 \\
\hline
\end{tabular}

ANOVA, analysis of variance; SS, sum of squares; MS, mean sum of squares; $F, f$-statistic; $d f$, degrees of freedom.

${ }^{*} p<0.05=$ statistically significant.

TABLE 14: Income statistics for the sample $(n=374)$.

\begin{tabular}{|c|c|c|c|c|}
\hline \multirow[t]{2}{*}{ Income (annual) } & \multicolumn{2}{|c|}{ Intrinsic motivation } & \multicolumn{2}{|c|}{ Extrinsic motivation } \\
\hline & Means & Std. Dv. & Means & Std. Dv. \\
\hline Below R120 000 & 4.26 & 0.51 & 3.98 & 0.57 \\
\hline R120 000-R239 999 & 4.19 & 0.60 & 3.84 & 0.52 \\
\hline R240 000-R359 999 & 4.21 & 0.46 & 3.89 & 0.50 \\
\hline R360 000-R479999 & 4.15 & 0.44 & 3.75 & 0.51 \\
\hline R480 000-R599 999 & 4.12 & 0.51 & 3.56 & 0.60 \\
\hline R600 000+ & 4.14 & 0.40 & 3.61 & 0.46 \\
\hline All groups & 4.17 & 0.49 & 3.75 & 0.53 \\
\hline
\end{tabular}

Std. Dv., standard deviation.

TABLE 15: ANOVA results according to income group.

\begin{tabular}{|c|c|c|c|c|c|c|c|}
\hline \multirow[t]{2}{*}{ Motivations } & \multicolumn{3}{|c|}{ Effect } & \multicolumn{2}{|c|}{ Error } & \multirow[t]{2}{*}{$F$} & \multirow[t]{2}{*}{$p$} \\
\hline & SS & $d f$ & MS & SS & MS & & \\
\hline Intrinsic & 0.65 & 5 & 0.13 & 87.55 & 0.24 & 0.55 & 0.74 \\
\hline Extrinsic & 7.19 & 5 & 1.44 & 97.56 & 0.27 & 5.43 & $0.00 *$ \\
\hline
\end{tabular}

SS, sum of squares; MS, mean sum of squares; $F, f$-statistic; $d f$, degrees of freedom.

$*, p<0.05=$ statistically significant.

both intrinsic and extrinsic motivations. In fact, cultural factors were shown to be the strongest influence on employees' motivation. The differences in terms of power distance and uncertainty avoidance, and differences in terms of masculinity/femininity between South Africa and Germany may account for this. As previously mentioned, culture is defined within the context of this study as the personality of a region and incorporates objectives and the criteria of a particular group of people (Worthley et al. 2009).

Furthermore, the study has revealed that South Africans show higher levels of intrinsic motivation than their German counterparts. The results show that South Africans demonstrate higher levels of intrinsic motivation than they do extrinsic motivation. This supports the findings of Nujjoo and Meyer (2012).

With regard to German respondents it was found that they too showed higher levels of intrinsic motivation than they did extrinsic motivation. This aligns with the findings of Stettes and Zimmermann (2013).

\section{Impact of gender on motivation}

The results of the study showed that in both countries females were more intrinsically motivated than what males were. This aligns with what was suggested by Stettes and Zimmermann (2013). The researchers believe that females may be slightly more intrinsically motivated than their male counterparts because of women often being tuned into their emotions and thus more able to be rewarded by them.

The results show that South African females have not only the highest levels of intrinsic motivation but also the highest levels of extrinsic motivation. It is, however, interesting to note that these differences were not found to be statistically significant, which, therefore, suggests that motivation is influenced more so by culture than it is by gender as culture was found to be a statistically significant difference.

\section{Impact of age on motivation}

The results show that intrinsic motivation at its highest within individuals of the ages 50-59. While this was a statistically 
significant difference, there were no statistically significant differences between age groups in terms of their extrinsic motivation. The works of Truxillo (2009) and Inceoglu et al. (2012) align with the findings of this study in that these authors also found that older employees (50-59) were more intrinsically motivated than their younger counterparts.

The researchers suggest that this may be because of the fact that older employees are entering the final stage of their career leading up to their retirement and are often no longer interested in working long hours to earn more money and feel less of a desire to climb the corporate ladder. Owing to this, older employees may be likely to be more motivated by intrinsic factors rather than extrinsic ones.

\section{Impact of income level on motivation}

In this study it was found that, contrary to what was suggested by Del Mar et al. (2010) and Renard (2015), the lowest income group actually demonstrated the highest levels of both intrinsic and extrinsic motivation. This, therefore, suggests that when designing these employees packages, consideration should be given to increasing both the intrinsic and extrinsic forms of reward as this group is demonstrated by both intrinsic and extrinsic sources.

\section{Implications for future research}

In this section, recommendations for further research are provided. An area for potential research could be the effects that extrinsic and intrinsic motivation have in organisations. This could explore the effects of intrinsic and extrinsic motivation on productivity, company success or even retention and engagement.

In particular, intrinsic motivation does not happen in a vacuum. In this study, it was not possible to compare motivation in different stages of a process or determine if motivation changes over time. A possible research question could be to ask how an organisation can increase and maintain motivation over time. In order to achieve this, a questionnaire could be sent to the same respondents over a period of time or several times.

Furthermore, motivation in relation to demographic variables should be researched in detail. In particular, the role of the management as a demographic variable could be looked into in more detail as management occupies a key role when it comes to motivation.

\section{Limitations of the study}

The researchers only limited the target group by a few characteristics, namely, working experience, nationality and tertiary education, for the participation of this research. The reason for this decision was to achieve a reasonable sample size. Further research could be undertaken with an increased number of limiting characteristics such as industrial field, managerial position or age group to make more specific assertions and inferences. In addition, this research was limited to two countries. Other countries could be taken into consideration to receive further insights.

Furthermore, although the online questionnaire had the advantage of being easy to access by the respondents and the data could be processed easily, the researchers had little control over composition of the sample or the industry to which the respondents belonged. It was not possible to calculate an accurate response rate because it was difficult to determine how many questionnaires were distributed. Although the respondents were provided with written instructions and the offer to contact the researcher in case of questions, misunderstandings may also have taken place.

\section{Implications for management}

This study has highlighted the importance of intrinsic motivation within employees and additionally has highlighted the essential role that culture plays in shaping one's motivation. As a result of these findings, management should have a well-formed and clear understanding of the culture within which their employees exist so that they are easily able to find manners of motivating their employees in accordance with this.

In order to fully develop intrinsic motivation, management could introduce four things into employees' work: meaningfulness, a sense of choice, a sense of competence and a feeling of progress or mastery, according to Thomas (2009). Meaningfulness involves showing employees that the work they are performing is valuable and is contributing to a larger overall purpose. Increasing employees' sense of choice occurs when employees are given autonomy and freedom to schedule their own work tasks, whereas increasing employees' sense of competence involves adequately developing employees' skills so that they may feel proud, satisfied and motivated when they are able to perform their work well. Finally, Thomas (2009) states that a feeling of progress is introduced into employees' work by allowing them to see what they have accomplished and by providing feedback when tasks are performed well so that the employee may feel that he or she is mastering a particular skill.

\section{Conclusion}

This study focused on the differences between South Africa and Germany with regard to intrinsic and extrinsic motivation. It was chosen as there were no studies, to date, which focused on these countries and their intrinsic and extrinsic motivation levels.

The findings of this study are, therefore, of importance as they attempt to address an empirical gap and they also provide insights into the role that culture plays in determining intrinsic and extrinsic motivation levels, as compared to other demographic variables such as gender, age or income. 
As some of the findings were inconclusive, more research is required to fully explore this topic.

\section{Ethical consideration}

Prior to the study being conducted, the researchers obtained the relevant permission to use the motivation instrument. This was done by contacting the author of the instrument in order to obtain a copy of the research instrument. Furthermore, participation in the research was completely voluntary and the respondents' anonymity was ensured.

\section{Acknowledgements}

The authors would like to acknowledge the valuable contribution of the respondents in this study, without which this study would not have been possible.

\section{Competing interests}

The authors have no competing interests which may have influenced the findings of this article.

\section{Authors' contributions}

A.G. completed the data collection, data analysis and literature review of this study during her Masters, under the supervision of R.J.S., S.A.S. compiled an article from the findings and literature, and edited the work. R.J.S. was involved in the editing of this article and the overseeing of this process.

\section{References}

Anyim, C.F., Chid, O.C. \& Badejo, A.E., 2012, 'Motivation and employees' performance in the public and private sector', International Journal of Business Administration 3, 31-40, https://doi.org/10.5430/ijba.v3n1p31

Arnolds, C., Boshoff, C. Mazibuko, N. \& Klemz, B., 2010, 'The motivational impact of job security, recognition, monetary incentives and training on the job performance of blue-collar workers', South African Journal of Labour Relations 34, 86-102.

Burke, B.L., Arkowitz, H. \& Dunn, C., 2002, 'The efficacy of motivational interviewing', in R.W. Miller \& S. Rollnick (eds.), Motivational interviewing: Preparing people for change, 2nd edn., pp. 217-250, Guilford Press, New York.

Cinar, O., Bektas, C. \& Aslan, I., 2011, 'A motivation study of the effectiveness of intrinsic and extrinsic factors', Economics and Management 16, 690-695.

Ciorbagiu-Naon, R., 2010, 'Modalities of non-financial motivations of employees within organizations', Annals of the University of Pertosani, Economics 10, 41-54.

Darling, K., Arm, J. \& Gatlin, R., 1997, 'How to effectively reward employees', Industrial Management 1, 1-4.

Deci, E.L., 1975, Intrinsic motivation, Plenum Press, New York.

Deci, E.L. \& Ryan, R.M., 1985, Intrinsic motivation and self-determination in human behaviour, Plenum Press, New York.

Deci, E.L. \& Ryan, R.M., 2008, 'Facilitating optimal motivation and psychological wellbeing across life's domains', Canadian Psychology 49, 14-23. https://doi. org/10.1037/0708-5591.49.1.14

Del Mar Salinas-Jimenez, M., Arte, C. \& Salinas-Jimenez, F.J., 2010, 'How educational attainment, occupational and wage-earner statuses attract life satisfaction? A gender perspective study', Journal of Happiness Studies 14, 367-388. https://doi. org/10.1007/s10902-012-9334-6

Francesco, A.M. \& Gold, B.A., 2005, International organizational behaviour, 2nd edn. Pearson Prentice Hall, Upper Saddle River, NJ.

Frey, B.S. \& Osterloh, M., 2002, Successful management by motivation: Balancing intrinsic and extrinsic rewards, Springer-Verlag Berlin, Heidelberg.

Grobler, P.A., Wärnich, S., Carrell, M.R., Elbert, F. \& Hatfield, R.D., 2011, Human resource management in South Africa, 4th edn., Cengage Learning, Andover.

Hair, J.F., Black, W.C., Babin, B.J. \& Anderson, R.E., 2010, Multivariate data analysis, 7th edn., Pearson Education Inc., Upper Saddle River, NJ.
Halepota, H.A., 2005, 'Motivational theories and their application inconstruction', Cost Engineering 4, 14-18.

Hennessey, B.A., 2000, 'Self-determination theory and the social psychology of creativity', Psychological Inquiry 11, 293-298.

Hofstede, G., 2001, Culture's consequences: Comparing values, behaviours, institutions, and organizations across nations, 2nd edn., Sage Publications, Thousand Oaks, CA.

Inceoglu, I., Bartram, D. \& Segers, J., 2012, 'Age-related differences in work motivation', Journal of Occupational an Organizational Psychology 85, 300-329. https://doi. org/10.1111/j.2044-8325.2011.02035.x

Jalilvand, M.R. \& Ebrahimabadi, F., 2011, 'The effects of demographic characteristics on employees' motivation to participate in the in-service training courses based on the modified expectancy theory', Canadian Social Science 7(3), 150-158.

Kaiser, L.C., 2014, Job satisfaction and public service motivation: IZA Discussion Paper No. 7935, North-Rhine Westphalia University of Applied Sciences for Public Administration, Public Administration, Dusseldorf.

Khalid, K., Salim, H. \& Loke, S.P., 2011, 'The key components of job satisfaction in Malaysia water utility industry', Journal of Social Sciences 7, 550-556. https://doi. org/10.3844/jssp.2011.550.556

Khan, N.S., Riaz, A. \& Rashid, M., 2011, 'The impact of work content, working conditions, career growth on employee motivation', Interdisciplinary Journal of Contemporary Research in Business 3(3), 1428-1434.

Malhotra, N.K., 2010, Marketing research: An applied orientation, 6th edn., Pearson Education Inc., Upper Saddle River, NJ.

Molander, C., 1996, Human resources at work, Chartwell-Bratt, Lund.

Mundhra, D.D. \& Jacob, W., 2011, 'Intrinsic motivators in the Indian manufacturing sector: An empirical study', The Journal of Business Perspective 14, 275-284. https://doi.org/10.1177/097226291001400404

Nawab, S., Bhatti, K.K. \& Shafi, K., 2011, 'Effect of motivation on employee's performance', Interdisciplinary Journal of Contemporary Research in Business 3, 1209-1216

Nujjoo, A. \& Meyer, I., 2012, 'The relative importance of different types of rewards for employees motivation and commitment in South Africa', SA Journal of Human Resource Management 10, 1-10. https://doi.org/10.4102/sajhrm.v10i2.442

Osterloh, M. \& Frost, J., 2002, 'Motivation und Wissen als strategische Resourcen', in B.S. Frey \& M. Osterloh (eds.), Managing motivation, 2nd edn., pp. 43-68, Gabler Verlag, Wiesbaden.

Perkins, S.J. \& White, G., 2009, Reward management: Alternatives, consequences and contexts, 1st edn., CIPD, London.

Phillips, J.M. \& Gully, S.M., 2012, Strategic staffing, 2nd edn., Pearson Prentice Hall, Upper Saddle River, NJ.

Pink, D.H., 2009, Dan Pink über die überraschende Wissenschaft der Motivation, viewed 21 February 2013, from http://www.ted.com/talks/dan_pink_on_ motivation.html

Pink, D.H., 2011, Drive: The surprising truth about what motivates us, Penguin Groups, New York.

Predendergast, C., 2008, 'Intrinsic motivation and incentives', American Economic Review: Papers \& Proceedings 98, 201-205. https://doi.org/10.1257/aer.98. 2.201

Qayyum, A. \& Sukirno, D., 2012, 'Motivation and the role of demographics: The banking industry of Pakistan', Global Business and Management Research: An International Journal 4, 1-14.

Renard, M., 2015, An international study on the influence of intrinsic rewards on the intrinsic motivation, work engagement and retention of employees in non-profit organisations, Unpublished doctoral dissertation, Nelson Mandela Metropolitan University, Port Elizabeth.

Robbins, S.P. \& Judge, T.A., 2011, Organizational behaviour, 14th edn., Pearson, Hoboken, NJ.

Ryan, R.M. \& Deci, E.L., 2000, 'Self-determination theory and the facilitation of intrinsic motivation, social development, and well-being', American Psychologist 55, 68-78. https://doi.org/10.1037/0003-066X.55.1.68

Sansone, C. \& Harackiewicz, J.M., 2000, Intrinsic and extrinsic motivation: The search for optimal motivation and performance, Academic Press, London.

Schmuck, P., Kasser, T. \& Ryan, R.M., 1999, 'Intrinsic and extrinsic goals: Their structure and relationship to well-being in German and U.S. college students', Socia Indicators Research 50, 225-241. https://doi.org/10.1023/A:1007084005278

Smith, K.T., 2010, 'Work-life balance perspectives of marketing professionals in generation Y', Services Marketing Quarterly 31, 434-447. https://doi.org/10.1080/ 15332969.2010.510724

Snelgar, R.J., Renard, M. \& Venter, D., 2013, 'An empirical study of reward preferences of South African employees', SA Journal of Human Resource Management 11 1-14. https://doi.org/10.4102/sajhrm.v11i1.351

Stettes, O. \& Zimmerman, A., 2013, Toller boss, toller job, viewed 17 August 2013, from http://www.iwkoeln.de/de/infodienste/iwd/archiv/beitrag/arbeitszufriedenheittoller-boss-toller-job-116970

Taylor, F.W., 2007, The principles of scientific management, Biblio Bazaar (original work published 1911), Charleson, SC

Thomas, K.W., 2009, Intrinsic motivation at work: What really drives employee engagement, Berrett-Koehler Publishers, San Francisco, CA. 
Truxillo, D.M., 2009, 'Age, work motivation and potential for age-based differential validity for personality measures', Industrial and Organizational Psychology: Perspectives on
Science and Practice 2, 106-108. https://doi.org/10.1111/j.1754-9434.2008.01116.x

Udechukwu, I.I., 2009, 'Correctional officer turnover: Of Maslow's needs hierarchy and Herzberg's motivation theory', Public Personnel Management 38(2), 69-82. https://doi.org/10.1177/009102600903800205

Vaitkuviene, L., Balvociute, R. \& Stoskus, S., 2010, 'The comparative analysis of employee motivation tools: The case of Lithuanian and Swedish manufacturing companies', Oranizciju Vadyba 3, 97-113.

Van Rooyen, L., Du Toit, D.H., Botha, E. \& Rothmann, S., 2010, 'Artisan retention in an organisation in South Africa', SA Journal of Human Resource Management 8, 1-8.
Worthley, R., Macnab, B., Brislin, R., Ito, K. \& Rose, E.L., 2009, 'Workforce motivation in Japan: An examination of gender differences and management perceptions', The International Journal of Human Resource Management 20, 1503-1520. https://doi.org/10.1080/09585190902983421

Zani, R.M., Rahim, N.A., Junos, S., Samanol, S., Ahmad, S.S., Mercian, F.M.I.M., et al., 2011, 'Comparing the impact of financial and non-financial rewards towards organizational motivation', Interdisciplinary Journal of Contemporary Research in Business 3, 328-334.

Zobal, C., 1999, 'The "ideal” team compensation system - An overview, part II', Team Performance Management 5, 23-45. https://doi.org/10.1108/1352759991026 3125 